\title{
Eyes wide shut? A conceptual and empirical critique of methadone maintenance treatment
}

\author{
Fischer, B ; Rehm, J ; Kim, G ; Kirst, M
}

DOI: https://doi.org/10.1159/000081410

Posted at the Zurich Open Repository and Archive, University of Zurich ZORA URL: https://doi.org/10.5167/uzh-96412

Journal Article

Published Version

Originally published at:

Fischer, B; Rehm, J; Kim, G; Kirst, M (2005). Eyes wide shut? A conceptual and empirical critique of methadone maintenance treatment. European Addiction Research, 11(1):1-12.

DOI: https://doi.org/10.1159/000081410 


\title{
Eyes Wide Shut? - A Conceptual and Empirical Critique of Methadone Maintenance Treatment
}

\author{
Benedikt Fischer ${ }^{a, b}$ Jürgen Rehm ${ }^{a, b, c}$ Gregory Kim ${ }^{a, b}$ Maritt Kirst $^{b}$ \\ a University of Toronto, ${ }^{b}$ Centre for Addiction and Mental Health, Toronto, Canada; \\ ${ }^{\mathrm{c}}$ Addiction Research Institute, Zurich, Switzerland
}

\section{Key Words}

Opioid dependence $\cdot$ Methadone maintenance treatment $\cdot$ Treatment evaluation - Quality of life • Self-medication

\begin{abstract}
Background: Methadone maintenance treatment (MMT) has been the 'gold standard' pharmacotherapy treatment for illicit opioid dependence for over 30 years. It has been widely evaluated, and is generally claimed to be 'effective'. Methods: The objective of this paper is to review the rationale of MMT as an intervention for a biomedical disorder with primary social objectives as well as the methodological quality and evidence of MMT outcome research. Data sources included opioid dependence treatment practice, review and outcome research literature (1965-2001) in the form of peer-reviewed articles, books, monographs and reports that are preeminently cited and reviewed international studies on MMT. Results/Data Synthesis: Rigorous and appropriate evaluation (i.e., RCTs, intent-to-treat, patient-centered) methods in MMT evaluations are rare. Evidence of MMT's effectiveness on primary treatment objectives is mixed and appears to be largely partial and short-term. Positive outcomes may be the result of selection effects of compliant patients and loss in proportion when more rigorous standards of analysis are applied. Conclusions: The quality of existing MMT research, and evidence for its general effectiveness are limited. Key concepts of self-
\end{abstract}

medication and psychiatric comorbidity are largely ignored in MMT treatment and research frameworks, although they may serve to explain MMT's limited treatment success. Emerging new opioid pharmacotherapies require the fundamental review of the existing MMT paradigm as well as the application of rigorous and appropriate evaluation methods for future treatment.

Copyright $(2005$ S. Karger AG, Basel

\section{Introduction}

Illicit opioid dependence is a century-old phenomenon, and despite its illegal context, the parameters and implications of this health problem are fairly well evidenced. There are an estimated 1.0-1.5 million illicit opioid users in Western Europe, North America and Oceania combined. [1-4] The huge mortality (direct, such as overdose; indirect, such as AIDS), morbidity and social cost impact of illicit opioid dependence, especially as they have increased over recent decades, have been extensively documented [1-4].

For the past three decades, the main treatment response to the phenomenon of illicit opioid dependence has been opioid pharmacotherapy in the form of 'methadone maintenance treatment' (MMT). The treatment builds on pioneering research in North America in the 1960s and the subsequently well publicized writings of Dole and Nyswander [5, 6]. Since then, MMT availability has continuously expanded, and the vast majority of

\section{KARGER}

Fax +4161306 1234 E-Mail karger@karger.ch www.karger.com
(C) 2005 S. Karger AG, Basel 1022-6877/05/0111-0001\$22.00/0

Accessible online at:

www.karger.com/ear
Benedikt Fischer, PhD

Department of Public Health Sciences, University of Toronto

McMurrich Bldg., 109C, Toronto, Ont., M5S 1A8 (Canada)

Tel. +1 416535 8501, Fax +1 4162604156

E-Mail benedikt.fischer@utoronto.ca 
the estimated 250,000-400,000 opioid-dependent individuals in treatment in Western Europe, North America and Oceania are receiving MMT [7].

Over the years, hundreds of evaluation studies on MMT have been conducted. At the beginning of the 1990s, MMT was seen as 'probably the most evaluated form of treatment in the field of drug abuse treatment' [8]. The predominant conclusion has been that MMT is an 'effective treatment for heroin addiction' [9]. A recent NIH research review, demanded barrier-free 'access to MMT' to 'all who need it' [10]. Evolving treatment systems (in emerging economies and the former socialist countries) are establishing MMT as the foundation for opioid dependence treatment. Thus, MMT has been established as the 'gold standard' of opioid dependence treatment against which newly evolving alternative opioid pharmacotherapy agents are automatically evaluated $[8,11,12]$.

The basic idea underlying MMT is that opioid dependence is a 'medical disorder characterized by predictable signs and symptoms' materializing at the genetic, molecular and neuronal levels [10]. The crucial problem of opioid dependence is defined as the subject's 'persistent or recurring craving' for opioids, causing the negative consequences of illicit opioid use [13]. MMT functions as a long-acting opioid substitute and 'narcotic blockade' preventing euphoria from additional heroin use; it therefore eliminates the negative consequences of opiate withdrawal and allows for the effective 'rehabilitation' of the opioid-dependent individual $[5,13,14]$. Over the years, general shortcomings of MMT have been recognized and debated, but none of them have managed to effectively challenge the predominant view of MMT as being categorically 'effective'. Rather, the shortcomings were seen as being correlated to intrinsic or micro-details in treatment provision, i.e., dosing, psychosocial treatment, incentives and rewards, allowing for fine tuning towards 'optimal MMT' $[9,15,16]$. Emerging new opioid pharmacotherapy regimes have been cast as either equally effective alternatives to MMT (i.e., buprenorphine) or as a 'last resort' treatment for a highly problematic, yet marginally small population of patients (i.e., heroin) [7, 17, 18], therefore not challenging the existing hegemony of MMT in opioid dependence treatment.

The central purpose of this paper is to provide an evaluative review and analysis of current practices and outcomes of opioid dependence treatment and research in light of the long history of MMT and the emerging diversity of other opioid pharmacotherapy agents.

\section{MMT's Cross-Eyed Mission? Biomedical Treatment for Social Rehabilitation}

In the context of the predominant biomedical models of illicit opioid dependence featuring patients suffering from 'medical abnormalities and behavioral destabilization' [19], a closer look at the primary expected objectives and outcomes of MMT reveals a peculiar slant. These objectives are characterized by two main features. First, MMT features main objectives of a social or a utilitarian nature. Consequently, the 'success' or 'effectiveness' of MMT is primarily operationalized by indicators that occur in or impact on larger, societal levels, rather than focusing on the individual patient's subjective health status or well-being. For example, reductions in patients' criminal activity have traditionally been listed as a main objective of MMT as well as a primary outcome for many efficacy studies [8-10, 20, 21]. Other usual endpoints include 'social functioning' or 'social productivity' (including employment, care for family or children or even 'marriage', etc.). While the patient's health status has been an intervention goal and object of inquiry in many MMT evaluations, an increasing emphasis has been put instead on either public health perspectives (i.e., health problems or health risks incurred to others, e.g. through the spread of infectious disease) or the expenditure of health care resources [8-10, 20, 21].

In addition to criminality and social functioning, it is usually the elimination or reduction of the patient's illicit (opioid and non-opioid) drug use that is used as a major endpoint in MMT [8-10, 20, 21]. While this aspect, at first glance on 'common sense' grounds, may appear to be correlated to the patient's direct well-being, explicit empirical evidence for this alleged linkage is peculiarly absent from most MMT evaluations. It is not clear, however, what biological basis exists to assume that opioid 'narcotic blockade' (in the form of MMT) would alleviate a human agent's craving for or even dependence on other drugs, such as marijuana or cocaine. At this end, MMT practice and assessment seems also starkly influenced by abstract social (or moral) norms, rather than concrete and practical measures in favor of the individual's health or well-being.

This utilitarian perspective in objectives and assessment of the supposed biomedical treatment of MMT is furthermore epitomized in the emerging wealth of 'social cost'- or 'cost-effectiveness'-based research of either untreated illicit opioid use or opioid pharmacotherapy treatment [11, 22-25]. 
With its primary focus on social outcomes as the expected effects of an intervention that supposedly aims at a 'brain-related medical disorder' [10], MMT presents a unique case in the framing of clinical intervention and evaluation practice. In fact, no other medical intervention for chronic disease with relapse potential we are aware of shares such a framework. As just one example, the respectively defined major endpoints for clinical trials of major depression therapy are not framed primarily as social but as individual benefits (see the outcomes of the respective Cochrane review at www.cochrane.org).

Evaluation of MMT has persistently stuck with societal measures of 'success' that are heavily influenced by societal determinants (rather than status or behavior anchored mainly in the patient's discretion, especially in the short-term). For example, 'employment', as a key measure, depends on a multitude of extrinsic parameters (like skills and education, labor market, etc.) far removed from the patient's drug use status or biomedical condition. Similarly, the measure of 'crime' (especially as indicated by institutional data) depends predominantly on the dynamics of law and enforcement [26, 27].

Furthermore, MMT evaluation approaches actually focusing on a patient-centered perception of health and wellbeing have played a completely marginal role within the considerable span of MMT research. 'Quality of life' (QoL) perspectives have emerged as an increasingly relevant framework within general clinical research elsewhere, including cancer, AIDS and psychiatry over the past 25 years $[28,29]$. Yet, a recent review of QoL perspectives within opioid pharmacotherapy treatment has revealed that this literature is limited to only 6 systematic studies, many of which struggle with methodological shortcomings [30]. Besides its peculiar marriage of biomedical causes with social engineering, MMT practice and research is, furthermore, almost entirely devoid of those perspectives of patient-centered health and well-being which have set new standards in the general field of clinical research [30].

\section{Short-Sighted? The Partial and Short-Term Impact of MMT}

Even a rather crude look at different empirical indicators of MMT's effectiveness indicates potentially fundamental shortcomings in the way the impact of MMT on its target population has traditionally been assessed. The conventional approaches to evaluate MMT are built on methodologies that largely ignore patient-centered views and on program dynamics that systematically de-select courses of treatment not producing MMT's desired effects. From a different point of view, MMT's effectiveness, when assessed on the basis of qualitative and patientcentered data, appears rather limited and short-term.

One of the key credos of MMT has been that treatment success or benefit is positively correlated with the 'duration of treatment' [20], and that the length of the patient's participation in treatment is a key predictor of positive results $[15,31]$. The logic as well as the mechanics behind these principles appear peculiar and shaped by tautological dynamics. MMT programs operationalize structures of norms and sanctions that systematically penalize and exclude patients who do not comply with the various rules of treatment - which at the same time constitute MMT's main success indicators. One preeminent example is the criteria concerning illicit opioid or other drug use. Many MMT programs operate with urinalysis tests, screening patients for continued illicit drug use [32]. In case of repeated noncompliance, patients usually receive some form of penalization, up to an 'involuntary discharge' and then appear as 'dropouts' in program statistics. Other reasons for dismissal include nonattendance of psychosocial treatment, missing methadone pick-ups or clinic appointments or the diversion of prescribed methadone [33-36]. Again, these rules are very specific to MMT - no diabetic or AIDS patient would be penalized by the treatment provider for not complying with the prescribed treatment regimen (even though compliance rates are similar to MMT). It is generally accepted knowledge that it is the 'most difficult' or noncompliant patients who leave MMT disproportionately and early on in treatment.

In fact, the criticism of assessments of MMT's effectiveness being selective and skewed is not new. Long ago, a widely ignored paper concluded that in key programs MMT's 'pro-social changes [...] were limited almost exclusively to "the minority" of the patients who were retained in the program for more than 3 years' and that 'the bulk of "reports on MMT's effectiveness" are based on analytic methods so weak that almost no conclusion can be drawn from them' [37]. In the current context, it is thus crucial to pay attention to the extensive empirical data showing that patient retention in MMT programs (measured at the 1-year point) is the exception rather than the rule. In a review of recent key studies indicating patient retention in MMT programs, National Institute on Drug Abuse reports a mean retention rate of $39.8 \%$ at 1 year (range: 25-60\%). [9] Conclusively, the review describes the evidence on retention rates in MMT as suggesting that 'about one third of the patients [...] remain for at least 1 year after admission' [9]. In a similar review, Bertschy 
[21] reports a 1-year retention rate of 54.4\% (range: 29 $73 \%$ ). This crude analysis presents us with the important insight that at least half of patients admitted to MMT have, for various reasons, left or been excluded from treatment, and are, on the basis of current practices, not part of any research analysis [20, 38, 39].

The limitations of MMT also become evident from the perspective of patient-centered QoL assessments of treatment effects [30]. The very few studies that have conducted systematic and standardized QoL assessments of MMT patients over time over the course of treatment provide important insights [40-42]. MMT patients retained in treatment indicate only moderate improvements in QoL status - from low original levels - after the initiation of treatment. However, these improvements only occur in the very first few months of treatment. After that, QoL levels in these studies plateau out or even reverse and thus constitute a short-term phenomenon [4042]. Torrens et al. [42, 43], in the only long-term QoL follow-up study of MMT patients, illustrate that even within the limited proportion of retained patients (1 year $=61 \%$; 3 years $=47 \%$ ), the vast bulk of QoL improvements occurred within the first 30 days of treatment, some between month 1 and 12, and no measurable improvements between month 12 and 36 .

There are also critical, yet often ignored dynamics intrinsic to the treatment itself which point to MMT's limited effectiveness for some illicit opioid users. The limited patient-centered literature [44-46] illustrates the broad 'dysphoric' dynamics of methadone and how this can negatively impact on patients' lives. Patient accounts have described the side effects of methadone as severely discomforting, disabling, numbing and tiring, in essence providing a powerful 'sedation' or 'blockade' effect barring them from heroin's desired qualities [47-50]. The mechanics and settings of MMT may also add a negative effect on the social and interpersonal aspects MMT patients' lives. The loss of the daily thrill, hassle and challenges of illicit drug scoring, the absence of a job, skills or employment prospects, unstable personal, social, financial or housing situations plus the rigorous, yet often punitive routine of MMT program requirements (including daily visits, urine tests, psychosocial treatment) have been described as putting a debilitating and demotivating face on many patients' daily life realities, and thus reducing their chances of retention and success in treatment $[44,51]$.

With the above data, we would like to offer the interim conclusion that current knowledge and beliefs about the 'effectiveness' of MMT treatment are based on the one hand on highly selective and partial assessment perspectives, while on the other hand they appear to ignore the evidence of severe limitations as indicated by patientcentered evaluation methods (i.e., QoL).

\section{MMT: Effective Treatment or Selection of Compliance?}

Efficacy is traditionally assessed in randomized clinical trials (RCT). Even though the extent of literature on MMT is large (a MEDLINE search on methadone and maintenance in June 2001 revealed 1,825 hits), there are very few RCTs on efficacy of MMT vs. placebo [8, 19, 52-54]. While these trials show significant improvements in outcomes such as illegal drug use, reincarceration, or treatment retention, they are plagued by various methodological problems. Most studies are based on small numbers of subjects, follow-up times are short (mostly 12 months or shorter), and all RCTs were conducted in countries where MMT at the time was the only pharmacotherapy available, and with limited availability. Thus, under these circumstances, retention rates may have been artificially pushed higher as dropping out from the trial may have meant the subjects' loss of a unique opportunity for pharmacotherapy [55].

The other evidence usually cited to show MMT effectiveness consists of observational studies. The study by Ball and Ross [15], another often-cited 'classic' on the effectiveness of MMT, has the following methodological problems: it was conducted in a system (US) with severe lack of adequate treatment alternatives, and the sampling overemphasized cases with long retention in treatment (35.5\% were in treatment for 3 years and over, and another $34.4 \%$ for 1 up to 2.9 years). Thus, the effectiveness results could be mainly interpreted as showing effects for those who were compliant with the (often very strict) regimes of the treatment centers. The GAO study [56] is one of the largest MMT studies conducted. It obtained data on narcotics use from 5,600 patients enrolled in MMT for at least 6 months. However, such a design, again, favored positive outcomes, as all the early dropouts (54\%) were not included in the statistical analysis, 10 out of 24 programs failed to meet the standard for success, since less than $20 \%$ of patients enrolled for at least 6 months were still injecting heroin [56]. Secondary analysis [57] provided evidence that mean dose of methadone predicted both retention and continued illicit heroin use, and the results were interpreted as supporting the assumption of effectiveness of MMT [20]. 
In sum, the quality and methodological standards of the evidence on the effectiveness of MMT are limited and far less impressive than usually cited $[10,20,58]$. The minority of patients who make it through the initial 1824 months of MMT present good odds of constituting a cluster whose treatment performance indicates improvement on the standard outcome measures. It is not clear, however, whether these improvements demonstrate 'true' treatment effects or are a result of systematic selection of compliant patients.

\section{MMT and 'Other Drug Use': Ambiguous Effects and Neglected Evidence}

Patients' other drug use (mostly cocaine, alcohol, marijuana, benzodiazepines and nicotine) during MMT has become increasingly important as a treatment evaluation endpoint. This development has occurred for several reasons. One of the pressing reasons has been that "other drug use', especially cocaine use, has become more prevalent among opioid addicts since the 1980s. Also, MMT has been utilized increasingly for addicts with polydrug dependence $[38,59,60]$.

While many reviews state that methadone is also effective in reducing cocaine consumption [10, 20, 61], results supporting this claim are ambivalent at best. In one of the RCTs cited above [19] no significant cocaine reduction effect emerged, e.g. the MMT group had no significantly different results than the control group. Once again, studies cited regularly supporting the effectiveness of MMT for cocaine use reduction are burdened with methodological problems [38, 61]. The critical issue concerns study designs that do not adjust for dropouts. An illustration: The outpatient methadone treatment outcome data of Hubbard et al. [62] reflects a 20\% reduction in weekly cocaine use among patients 1 year after treatment entry. However, the study sample size diminished through attrition from 1,203 patients at treatment admission to 727 patients at 1-year follow-up, with 476 patients $(39.6 \%)$ having dropped out of treatment over the course of the first year.

The implications of this problem can be illustrated by two hypothetical, yet realistic better-and-worse scenario calculations. If $80 \%$ of the 476 treatment dropouts in the study by Hubbard et al. [62] still used cocaine at the point of follow-up, then $45 \%$ of the total base sample $(n=1,203)$ would be using cocaine after 1 year of treatment. This first hypothetical scenario would indicate an overall increase in cocaine use over time when taking into account the behavior of all original patients. In a second hypothetical calculation, if $60 \%$ of the 476 treatment dropouts still used cocaine, then $37 \%$ of the total base sample would be using cocaine after 1 year of treatment. This second hypothetical situation would mean a minimal reduction of cocaine use in the treatment sample over preadmission rates, likely below statistical significance levels. Intent-totreat analysis where a negative outcome is assumed for all dropouts would thus lead to a conclusion that a marked increase in cocaine use occurred for the sample over the course of study.

In the study by Ball and Ross [15], frequently cited to support the effectiveness of MMT at reducing cocaine use, the sample was skewed in a way to include many patients with long treatment histories. In short, such studies show that individuals retained in treatment for longer times can reduce their cocaine use, but they lack untreated controls and patients' drug use histories. Therefore, these studies cannot exclude the alternative hypothesis that these positive findings are simply the result of sample selection effects. In untreated controls, there may well be a minority indicating cocaine use reductions, yet usually no empirical information is available about them.

Other studies have reported mixed effects or even increases in patients' cocaine use during MMT. In the Vancouver VIDUS cohort of injection drug users, cocaine use declined from 60 to $37 \%$, and speedball use decreased from 28 to $22 \%$, but crack use increased from 18 to $36 \%$ for the total cohort over an observation period of 3 years among a sample of 174 subjects who were consistently enrolled in MMT. However, a snapshot comparison between the subjects in MMT (174) with those not in MMT (882) showed that drug use was essentially the same in the two groups [63]. Best et al. [64] found increased use of crack cocaine over the course of MMT, and $16.5 \%$ of patients (based on 91\% follow-up rate) initiated crack cocaine use in the first 6 months of treatment. This example is also important because other examples of increased cocaine use occurred during the time when cocaine became more available in the respective sociocultural setting, and thus comparisons may be confounded by extrinsic determinants of time and place [65].

In sum, we have an ambivalent picture of the effects of MMT on the prevalence of cocaine use among patients. Cautious interpretation of the available wealth of empirical data would suggest no clear overall effect. The same seems true for other substances for which studies have found increases in use during MMT even for treatment 'responders' [66, 67]. But overall, based on methodologically weak studies, evidence for decreases, increases and 
stable levels of other drug use can be found among MMT patients. Since methodological weaknesses tend to favor positive results (e.g., there is no reason to assume that the select samples of compliant patients are doing worse than the dropouts), intent-to-treat analysis with the assumption of negative results for dropouts would usually result in findings of no changes or increases.

\section{The Eye That Might See: Comorbidity and Self-Medication}

Even when the pure 'biochemical intervention' perspective of MMT is assumed, there is no rational basis for expecting that this intervention will lead to an alteration of the patient's opioid dependence status or a reduction of other non-opioid drug use. Nevertheless, these hypothetical effects of reduced illicit drug use have a long history of being flagged as a major benefit of MMT, and frequently data are presented that demonstrate MMT's supposed effectiveness in producing these effects $[19,68$, 69]. Our above methodological critique suggested that there are no solid empirical grounds to assert that MMT is consistently effective in reducing illicit drug use among patients. In fact, sporadic evidence suggests that the contrary effect may be true.

Although there has been a debate about the measuring of the prevalence of psychiatric conditions among drug users in treatment institutions [70] and about the causality of covariation between psychiatric and substance use disorders [71], there is substantial evidence that such symptoms are disproportionately prevalent and nonrandomly distributed among illicit opioid users. For example, the ECA study [14] documented on the basis of a large-scale representative population survey that psychiatric comorbidity prevalence amounted to as much as $65.2 \%$ in illicit opioid user populations and the prevalence was 6.7 times that of the general population. In particular, anxiety and mood disorders were prevalent in nearly one third of subjects, and psychotic features occurred in more than $10 \%[14,72,73]$. Various studies of opioid or injection drug user cohorts suggested that approximately half of the individuals assessed met the diagnostic criteria for major depression as the primary psychiatric indication in this subpopulation [73-77]. Almost two thirds of a sample of drug using admissions cases to a psychiatric facility stated that they used illicit substances (opioids, cocaine or sedative-hypnotics) in response to 'feeling depressed' [78]. Abraham and Fava [79] found a temporal correlation between psychiatric mood disorder symptoms and subsequent cocaine and alcohol dependence. The prevalence of use of stimulants among people with schizophrenia has been found to be significantly greater than that of control populations [80], and depressive features have been identified as a major determinant for smoking as well as an influence on the success rate of quitting attempts [81]. A number of studies found that mood and anxiety disorders are a significant predictor of illicit drug use for 'self-medication' purposes [78, 82].

While the high coprevalence of narcotic or stimulant drug dependence and psychiatric disorder symptoms is convincingly evidenced, it is Khantzian's [83] seminal work that has provided fundamental analysis on the correlation between specific psychiatric conditions and categories of drug dependence. Essentially, Khantzian suggests that drug-dependent individuals are not only predisposed to the use of psychoactive substances in order to 'medicate themselves for a range of psychiatric problems and painful emotional states' [83], but furthermore are 'attracted to and choose substances' [84] in order to cope with or 'self-medicate' specific or distinct mental health conditions. This appears particularly relevant for the subgroup of patients for whom psychoactive drug use has been empirically found to be a causal consequence of psychiatric symptoms [71, 85]. For instance, some drugdependent people seek out opioids to calm underlying feelings of anger, rage or aggression - utilizing the 'analgesic properties' of the substance in a broad sense. Cocaine is sought out primarily by some people for the drug's ability to alleviate psychological distress associated with depression and attention deficit disorder [79, 83, 86].

Looking from two angles, the self-medication perspective seems essential for a constructive understanding and synthesis of our observations in regard to the current realities of MMT. First, if one accepts the proposed role of a fundamental causal contribution of psychiatric disorders to the substance use patterns in at least some illicit opioid users, the aims of MMT in its current framework and practice are off target. The 'chemical intervention' component of MMT is not a suitable or effective response to any of the various primary psychiatric symptoms observed in the majority of illicit opioid users. The much emphasized 'psychosocial treatment' components in MMT [15, 87] - delivered predominantly in the form of occasional individual or group counseling, skills development, self-help - cannot be considered as adequate efforts to provide therapy for illicit substance users' long-standing psychiatric disorders, such as mood and anxiety disorders, schizophrenia or other psychotic disorders. As such, MMT in its current approach, may simply be ad- 
dressing surface symptoms, while neglecting the fundamental processes underneath the pathological etiology of illicit opioid and other drug use.

\section{Conclusions: Opioid Pharmacotherapy Treatment - Quo Vadis?}

In this paper, we have critiqued the conceptual fundamentals as well as evaluation approaches and evidence of almost four decades of MMT, the central treatment modality for the treatment of hundreds of thousands of opioid-dependent individuals in the Western world. Our basic conclusions are that fundamental rethinking is needed in order to achieve meaningful progress of opioid pharmacotherapy practice in the 21 st century.

One of the central contentions emerging from our review is that it is principally and practically not sensical to maintain opioid pharmacotherapy as an exotic bulwark of medicine artificially designed to serve primarily societal goals, while emphasizing patient-centered circumstances, well-being and QoL. There is neither a pragmatic rationale nor good reason to expect that biochemical treatment for opioid dependence, as provided by MMT, will produce 'social betterment' for individuals or populations as socially marginalized or disadvantaged as most illicit opioid users. Hardly any of the longstanding main goals of MMT have a direct or necessary link to patients' perceived well-being or QoL, which has become a central measure and guiding pole for the assessment of treatment for chronic illnesses [88, 89]. Although conceptual and sensitivity questions exist with regard to the appropriate measuring of QoL [30, 90], these perspectives - while acknowledging certain utilitarian limitations should form the basis for future assessment of whether we are providing 'good' or 'bad' treatment in the form of MMT and beyond. Physical and mental health status and improvement - measured by standard indicators as well as the patient's experiences - must present the key and authoritative measures for the effects and quality of MMT care. Meaningful analysis of treatment effectiveness should use comparisons with a control condition (with $\mathrm{RCT}$ as the desirable standard) and utilize intent-to-treat methodology to exclude effects produced by self-selection. While the former presents ethical dilemmas, especially with populations like substance-dependent patients, it is a minimal scientific standard so far drastically ignored in hundreds of MMT outcome studies.

We have, furthermore, suggested the necessity of understanding illicit opioid and other drug use during opi- oid pharmacotherapy within the psychiatric comorbidity and self-medication framework. If taken seriously in the real life context of illicit opioid use and treatment, this perspective would not only eliminate the challenging expectation of reductions of cocaine and other drug use among MMT patients, but also provide an explanation for why such behaviors may become exacerbated during treatment for some. In fact, the clinical MMT research field has for a long time presented clues that strengthen these observations and help to support conclusions for clinical practice. It is becoming more evident that MMT typically hosts distinct clusters of patients with different patterns and needs in terms of psychiatric and self-medication dynamics determining their drug use profile. Studies prior to the 1980s on the effectiveness of MMT typically noted substantial increases in the consumption of alcohol. In certain patient subclusters, increases in alcohol use during treatment are not dissimilar to cocaine in terms of psychoactive effect profiles, properties and dynamics, especially from a self-medication point of view $[79,91]$. Viewed within the self-medication framework, empirical categorization of MMT patients into distinct psychiatric indication clusters, as demonstrated by Strain et al. [77], meaningfully complements and supports these conclusions. These insights, taken in synthesis, suggest that we ought to become much more sensitive in our understanding of opioid and other drug use disorders as driven and influenced by psychiatric-structural dispositions, for which opioid pharmacotherapy alone cannot be expected to provide a sufficient intervention.

Thus, what is necessary are realistic and differentiated approaches for the future of meaningful and patient-centered opioid pharmacotherapy with the principal goal of maximized patient health and well-being. First, we need thorough and comprehensive empirical data on the selfmedication dynamics of opioid users in and out of treatment. Secondly, the dynamics of distinct patterns and needs with regard to psychiatric comorbidity profiles in opioid dependence patients emphasize more strongly than before the need for differentiated treatment regimes within the broadening realm of opioid pharmacotherapy beyond conventional MMT. It may very well be the case that new regimes emerging in the increasingly diverse opioid pharmacotherapy landscape (including buprenorphine combinations, morphine, heroin, Dilaudid [18, 92] provide more sensitive and desirable responses in certain patient groups with diverse dispositions than traditional MMT.

Eur Addict Res 2005;11:1-14 


\section{References}

1 Farrell M, Verster A, Davoli M, Nilson M, Merino $\mathrm{P}$ : Reviewing current practice in drug-substitution treatment in the European Union. Luxembourg, Office for Official Publications of the European Communities, 2000.

2 European Monitoring Centre for Drugs and Drug Addiction: Annual report on the state of the drugs problem in the European Union. Luxembourg, Office for Official Publications of the European Communities, 2000.

3 Hall W, Lynskey M, Degenhardt L: Heroin use in Australia: Its impact on public health and public order. Sydney, National Drug and Alcohol Research Centre, 1999.

4 Kuo I, Fischer B, Vlahov D: Consideration of a North American heroin-assisted trial for the treatment of opiate-dependent individuals. Int J Drug Policy 2000;11:357-370.

5 Dole V, Nyswander M: A medical treatment for diacetylmorphine (heroin) addiction. J Am Med Assoc 1965;193:646-650.

6 Halliday R: Management of the Narcotic Addict. Br Columbia Med J 1963;5:412-414.

7 Fischer B, Rehm J, Kirst M, Casas M, Hall W, Krausz M, Metrebian N, Reggers J, Uchtenhagen A, van den Brink W, Van Ree J: Heroinassisted treatment as a response to the public health problem of opiate dependence. Eur J Public Health, under review.

8 Farrell M, Ward J, Mattick R, Hall W, Stimson G, Des Jarlais D, Gossop M, Strang J: Methadone maintenance treatment in opiate dependence: A review. Br Med J 1994;309:9971001.

9 NIDA: Methadone Maintenance Treatment: Translating research into policy. Bethesda, National Institute on Drug Abuse, 1995.

10 National Institutes of Health: National consensus development panel on effective medical treatment of opiate addiction. JAMA 1998; 280:1936-1943.

11 Rehm J, Fischer B: Heroingestützte Therapie für Opiatabhängige weder Allheilmittel noch Teufelswerk. Suchttherapie 2000;01:57-62

12 Dole VP, Nyswander M, Kreek M: Narcotic blockade. Arch Int Med 1966;118:304-309.

13 Lowinson J, Marion I, Joseph H, Dole V: Methadone maintenance; in Lowinson $\mathrm{JH}$, Ruiz P, Millman RB, Langrod JG (eds): Substance Abuse: A Comprehensive Textbook, ed 2. Philadelphia, Williams \& Wilkins, 1992, pp 550-561.

14 Regier DA, Farmer ME, Rae DS, Locke BZ, Keith SJ, Judd LL, Goodwin FK: Comorbidity of mental disorders with alcohol and other drug abuse: Results from the Epidemiological Catchment Area (ECA) Study. JAMA 1990; 264:2511-2518

15 Ball JC, Ross A: The effectiveness of methadone maintenance treatment: Patients, programs, services and outcomes. New York, Springer, 1991.

16 Maxwell S, Shinderman M: Optimizing response to methadone maintenance treatment: Higher dose methadone. Heroin Addict Relat Clin Probl 2000;2:53-54.
17 Fischer B, Rehm J: The case for a heroin substitution treatment trial in Canada. Can J Public Health 1997;88:367-370.

18 Bammer G, Dobler-Mikola A, Fleming P, Strang J, Uchtenhagen A: The heroin prescribing debate: Integrating science and politics. Science 1999;284:1277-1278.

19 NIDA: Principles of Drug Addiction Treatment: A Research-Based Guide. Bethesda, National Institute on Drug Abuse, National Institutes of Health, 1999.

20 Ward J, Hall W, Mattick R: Role of methadone maintenance in opioid dependence. Lancet 1999;353:221-226.

21 Bertschy G: Methadone maintenance treatment: An update. Eur Arch Psychiatry Clin Neurosci 1995;245:114-124.

22 Wall R, Rehm J, Fischer B, Brands B, Gliksman L, Stewart J, Medved W, Blake J: The social cost of untreated opiate use. J Urban Health 2001;77:688-722.

23 Barnett P: The cost-effectiveness of methadone maintenance as a health care intervention. Addiction 1999;94:479-488.

24 Barnett P, Hui S: The cost-effectiveness of methadone maintenance. Mt Sinai J Med 2000;67:365-374.

25 Frei A, Greiner R, Mehnert A, Dinkel R: Socioeconomic evaluation of the trials for the medical prescription of opiates, final report; in Gutzwiller F, Steffen T (eds): Cost Benefit Analysis of Heroin Maintenance Treatment. Basel, Karger, 2000.

26 Fishman M: Crime waves as ideology. Soc Probl 1978;25:543.

27 Chambliss W: Criminal law in action. Santa Barbara, Hamilton, 1975, pp 1-477.

28 Wood-Dauphinee S: Assessing quality of life in clinical research: From where have we come and where are we going? J Clin Epidemiol 1999;52:355-363.

29 Sanders C, Egger M, Donovan J, Tallon D, Frankel S: Reporting on quality of life in randomised controlled trials: Bibliographic study. BMJ 1998;317:1191-1194.

30 Fischer B, Rehm J, Kim G: 'Quality of Life' (QoL) in illicit opiate addiction research and treatment: Concepts, evidence, questions; in Westermann B, Jellinek C, Bellman G (eds): Substitution: Zwischen Leben und Sterben. Weilheim, Beltz Deutscher Studien Verlag, in press.

31 Simpson DD, Sells SB: Effectiveness of treatment for drug abuse: An overview of the DARP research program. Adv Alcohol Subst Abuse 1982;51:7-29.

32 Wasserman D, Korcha R, Havassy B, Hall S: Detection of illicit opioid and cocaine use in methadone maintenance treatment. Am J Drug Alcohol Abuse 1999;25:561-571.

33 Chutuape M, Silverman K, Stitzer M: Use of methadone take-home contingencies with persistent opiate and cocaine abusers. J Subst Abuse Treat 1999;16:23-30.
34 Saxon A, Calsyn D, Kivlahan D, Roszell D: Outcome of contingency contracting for illicit drug use in a methadone maintenance program. Drug Alcohol Depend 1993;31:205214.

35 Rosenbaum M: A matter of style: Variation among methadone clinics in the control of clients. Contemp Drug Probl 1985;Fall:375399

36 Zweben JE: Counseling issues in methadone maintenance treatment. J Psychoactive Drugs 1991;23:177-190.

37 Kleinman P, Lukoff I, Kail B: The magic fix: A critical analysis of methadone maintenance treatment. Soc Probl 1977;25:208-214.

38 Fischer B, Kirst M, Rehm J, Marsh D, Bondy $\mathrm{S}$, Tyndall M: The phenomenon of so-called 'other drug use' among opiate addicts in the North American context: Evidence, consequences, questions; in Westermann B, Bellman G, Jellinek C (eds): Beigebrauch: Offene Grenzen der Substitution. Weilheim, Beltz Deutscher Studien Verlag, 2000.

39 Committee on Federal Regulation of Methadone Treatment and Institute of Medicine: Federal Regulation of Methadone Treatment. Rettig R, Yarmolinsky A (eds), Washington, National Academy Press, 1995.

40 Reno R, Aiken L: Life activities and life quality of heroin addicts in and out of methadone treatment. Int J Addict 1993;28:211-232.

41 Dazord A, Mino A, Page D, Broers B: Patients on methadone maintenance treatment in Geneva. Eur Psychiatry 1998;13:235-241.

42 Torrens M, San L, Martinez A, Castillo C, Domingo-Dalvany A, Alonso J: Use of the Nottingham Health Profile for measuring health status of patients in methadone maintenance treatment. Addiction 1997;92:707-716.

43 Torrens M, Domingo-Dalvany A, Alonso J, Castillo C: Methadone and quality of life. Lancet 1999;353:1101.

44 Fischer B, Chin A, Kuo I, Kirst M, Vlahov D: Opiate users' views on methadone and other opiate prescription treatment in Canada: A qualitative focus group study. Subst Use Misuse, in press.

45 Koester S, Anderson K, Hoffer L: Active heroin injectors' perceptions and use of methadone maintenance treatment: Cynical performance or self-prescribed risk reduction? Subst Use Misuse 1999;34:2135-2153.

46 Neale J: Drugs users' views of prescribed methadone. Drugs Educ Prev Policy 1998;5:3345.

47 Hunt D, Lipton D, Goldsmith D, Strug D, Spunt B: It takes your heart: The image of methadone maintenance in the addict world and its effects on recruitment into treatment. Int J Addict 1986;20:1751-1771.

48 Goldsmith D, Hunt D, Lipton D, Strug D: Le folklore de la methadone: Impact de certaines croyances sur le traitement. Psychotropes $1985 ; 2: 59-71$. 
49 Rosenbaum M, Murphy S: Getting the treatment: Recycling women addicts. J Psychoact Drugs 1981;13:1-13.

50 Brown B, Benn G, Jansen D: Methadone maintenance: Some client opinions. Am J Psychiatry $1975 ; 132: 623-626$.

51 Hunt G, Rosenbaum M: 'Hustling' within the clinic: Consumer perspectives on methadone maintenance treatment; in Inciardi J, Harrison L (eds): Heroin in the Age of Crack-Cocaine, ed 6. London, Sage Publications, 1998, pp 188-214.

52 Dole VP, Robinson J, Orraca J, et al: Methadone treatment of randomly selected criminal addicts. New Engl J Med 1969;280:13721375 .

53 Newman R, Whitehill W: Double-blind comparison of methadone and placebo maintenance treatments of narcotic addicts in Hong Kong. Lancet 1979;2:485-488.

54 Strain E, Stitzer M, Liebson IA, Bigelow G: Comparison of buprenorphine and methadone in the treatment of opioid dependence. Am J Psychiatry 1994;151:1025.

55 Rehm J, Uchtenhagen A, Dombrowski D: Metaanalyse schweizerischer Arbeiten zur Verwendung von Methadon als Substitutionsmittel bei der Behandlung von Opioidabhängigkeit. Zürich, Institut für Suchtforschung, 2001.

56 United States General Accounting Office: Methadone maintenance: Some treatment programs are not effective, greater federal oversight needed: Report to the Chairman, Select Committee on Narcotics Abuse and Control, House of Representatives. Washington, 1990, pp 1-37.

57 Newman R, Des Jarlais D: Criteria for judging methadone maintenance programs. JAMA 1991;265:2190-2191.

58 Ward J, Mattick RP, Hall W: Methadone maintenance and other opioid replacement therapies. Amsterdam, Harwood Academic, 1998.

59 Hunt D, Strug D, Goldsmith D, Lipton D, Spunt B, Truitt L, Robertson K: Alcohol use and abuse: Heavy drinking among methadone clients. Am J Drug Alcohol Abuse 1984;12: 147-164.

60 Hunt D, Strug D, Goldsmith D, Lipton D, Spunt B, Truitt L, Robertson K: An instant shot of 'aah': Cocaine use among methadone clients. J Psychoact Drugs 1984;16:217-227.

61 Fontaine P, Ansseau M: Aspects pharmacocliniques de la methadone. Encephale 1995;21: 167-179.

62 Hubbard R, Craddock S, Flynn P, Anderson J, Ethridge R: Overview of 1 year follow-up outcomes in the drug abuse treatment outcome study (DATOS). Psychol Addict Behav 1997; 11:261-278.
63 Tyndall MW, Brooks R, Currie S, Li K, O'Shaughnessy M, Schechter MT: Injection drug use among those on methadone maintenance treatment (abstract 346P). Can J Infect Dis 2000;11:66B.

64 Best D, Harris J, Gossop M, Farrell M, Finch E, Noble A, Strang J: Use of non-prescribed methadone and other illicit drugs during methadone maintenance treatment. Drug Alcohol Rev 2000;19:9-16.

65 Cushman P: Cocaine use in a population of drug abusers on methadone. Hosp Commun Psychiatry 1988;39:1205-1207.

66 Shaffer H, LaSalvia T: Patterns of substance use among methadone maintenance patients. J Subst Abuse Treat 1992;9:143-147.

67 Cochrane Review: LAAM maintenance vs. methadone maintenance for heroin dependence. The Cochrane Library. Oxford, Update Software, 2001.

68 Uchtenhagen A: Substitutionsbehandlung der Opiatabhangigkeit; in Helmchen H, Henn F, Lauter H, Sartorius N (eds): Psychiatrie der Gegenwart, ed 4. Berlin, Springer, 2000, pp 602-628.

69 Dobler-Mikola A, Pfeifer S, Müller V, Uchtenhagen A: Methadon- und Heroin- unterstützte Behandlung Opiatabhängiger im Vergleich. Zürich, Institut für Suchtforschung, 1998.

70 Raskin V, Miller N: The epidemiology of the comorbidity of psychiatric and addictive disorders: A critical review. J Addict Dis 1993;12: $45-57$.

71 Zimberg S: A dual diagnosis typology to improve diagnosis and treatment of dual disorder patients. J Psychoact Drugs 1999;31:47-51.

72 Rettig R, Yarmolinsky A: Federal regulation of methadone treatment. Washington, National Academy Press, 1995.

73 Krausz M, Degkwitz P, Kuhne A, Verthein U: Comorbidity of opiate dependence and mental disorders. Addict Behav 1998;23:767-783.

74 Brienza R, Stein M, Chen M-H, Gogineni A, Sobota M, Maksad J, Hu P, Clarke J: Depression among needle exchange program and methadone maintenance clients. J Subst Abuse Treat 2000;18:331-337.

75 Busto U, Romach M, Sellers E: Multiple drug use and psychiatric comorbidity in patients admitted to the hospital with severe benzodiazepine dependence. J Clin Psychopharmacol 1996;16:51-57.

76 Darke S, Swift W, Hall W, Ross M: Drug use, HIV risk-taking and psychosocial correlates of benzodiazepine use among methadone maintenance clients. Drug Alcohol Depend 1994; 31:31-36.

77 Strain E, Brooner R, Bigelow G: Clustering of multiple substance use and psychiatric diagnoses in opiate addicts. Drug Alcohol Depend 1991;27:127-134.
78 Weiss R, Griffin M, Mirin S: Drug abuse as self-medication for depression: An empirical study. Am J Alcohol Abuse 1992;18:121129.

79 Abraham H, Fava M: Order of onset of substance abuse and depression in a sample of depressed outpatients. Compr Psychiatry 1999; 40:44-50.

80 Schneier F, Siris S: A review of psychoactive substance use and abuse in schizophrenia. Patterns of drug choice. J Nerv Ment Dis 1987; 175:641-652.

81 Covey L, Glassman A, Stetner F: Cigarette smoking and major depression. J Addict Dis 1998; 17:35-46.

82 Gearon J, Bellack A, Rachbeisel J, Dixon L: Drug-use behavior and correlates in people with schizophrenia. Addict Behav 2001;26: 51-61.

83 Khantzian E: The self-medication hypothesis of addictive disorders: Focus on heroin and cocaine dependence. American J Psychiatry $1985 ; 142: 1264$

84 Blume A, Schmaling K, Marlatt G: Revisiting the self-medication hypothesis from a behavioral perspective. Cogn Behav Pract 2000;7: 379-384.

85 Mueser K, Drake R, Wallach M: Dual diagnosis: A review of etiological theories. Addict Behav 1998;23:717-734.

86 Castaneda R: Empirical assessment of the selfmedication hypothesis among dually diagnosed inpatients. Compr Psychiatry 1994;35: 180-184.

87 McLellan A, Arndt I, Metzger D, Woody G, O'Brien C: The effects of psychosocial services in substance abuse treatment. J Am MedAssoc 1993;269:1953-1959.

88 Gill T, Feinstein A: A critical appraisal of the quality of quality-of-life measurements. JAMA 1994;272:619-626.

89 Higginson I, Carr A: Measuring quality of life: Using quality of life measures in the clinical setting. BMJ 2001;322:1297-1300.

90 Carr A, Higginson I: Are quality of life measures patient centred? BMJ 2001;322:13571360.

91 Carroll K, Rounsaville B, Bryant K: Alcoholism in treatment-seeking cocaine abusers: Clinical and prognostic significance. Compr Psychiatry 1993;54:199-208.

92 Ritter A, Kutin J, Lintzeris N, Bammer G: Expanding treatment options for heroin dependence in Victoria: Buprenorphine, LAAM, naltrexone and slow-release oral morphine, New Pharmacotherapies Project-Feasibility Phase. Fitzroy, Australia, Turning Point Alcohol and Drug Centre Inc., 1997. 


\section{Comment}

\section{A. Uchtenhagen}

Zurich

In view of the worldwide application and ongoing expansion of opiate replacement therapies, there is much interest in sound scientific evidence regarding the merits and shortcomings of those therapies. Many of the arguments in Fischer's review of methadone maintenance treatment (MMT) could apply for other replacement therapies as well, and therefore it is all the more appropriate to discuss his arguments.

First, the 'cross-eyed mission': methadone maintenance as a biomedical treatment for social rehabilitation is far from being 'unique'. Most pharmacological interventions in psychiatry do not only focus on the patient's subjective health status or well-being, but on behavior that is impeding social functioning and/or inviting conflicts with others. Antidepressant, antianxiety and antipsychotic medications not only relieve symptoms, but also the many negative consequences of patient's behavior in the social context. Improved well-being may even be a consequence of improved social functioning and less conflict. It is a misleading approach to separate the subjective from the social aspects of psychiatric morbidity, as there are many interactive processes to be considered, and drug dependence is part of psychiatric morbidity.

However, it is true that quality of life (QoL) is an often neglected issue in methadone maintenance research. But if the studies mentioned in Fischer's article indicate improvements during the first few months in treatment, this should be considered to be a rather positive effect, in line with rapid improvements in health status. I may add that it would make more sense to assess more precisely what has improved in the subjective situation of maintenance patients and what has eventually worsened: from clinical experience one would expect improvements in health status and relief from impediments that are related to the daily need to satisfy the drug craving and to find the necessary means, but also a confrontation with many problems covered up so far and with the often depressing experience of what has been missed in life. Also the side effects of medications, the new despondency on the treatment program, the social isolation after loosening the ties to the drug scene are factors that reduce QoL. Without such a differentiation of positive and negative factors, assessment of QoL scores is of limited value.
The methodological shortcomings of evaluation studies are a serious issue. However, in a meta-analysis of 6 randomized controlled studies, an updated Cochrane review (known in medicine for their rigorous methodological standards) has evidenced that methadone appeared statistically more effective than non-pharmacological approaches in retaining patients in treatment and in the suppression of heroin use, but not statistically in criminal activity [Mattick et al., 2004]. In a recent randomized controlled study on methadone maintenance in prison as compared to untreated controls (waiting list), objective and subjective measures of opioid use were significantly reduced in the methadone group, as was sharing of syringes [Dolan et al., 2003].

Observational cohort studies often suffer from a weakness mentioned in Fischer's article: in contrast to an intention-to-treat design, many base their statistics on those who remain in treatment during the follow-up period. However, the National Treatment Outcome Research Study in England has published the findings of a 5 -year follow-up on a randomly selected sample from 54 programs included in the study (drug-free residential, community-based methadone maintenance and methadone reduction), independent of length of stay in the program and retention. The outcome of communitybased services using methadone is equivalent to the outcome of residential treatments and includes major improvements in many domains in comparison to baseline data: regular heroin use; non-prescribed methadone use; regular non-prescribed benzodiazepine use; regular cocaine powder use; injecting and sharing; psychological health symptoms; suicidal ideation, and selling drugs. For crack cocaine use and regular amphetamine use, outcomes were better in the sample from community-based services. Psychological health symptoms, suicidal ideation, acquisitive crime and selling drugs showed a marked decrease at year 2 and then a moderate increase until years 4-5, but did not reach the base-line high, for patients from community-based and from residential services [Gossop et al., 2001]. Some major lessons come from this study: patients in residential treatment in general had more serious problems than those in the outpatient programs, but the overall outcomes from both settings are quite similar. While three quarters of methadone patients showed a good response to treatment, one quarter did not and is a matter of concern. However, the range and magnitude of positive outcomes from methadone programs complement the findings from randomized controlled studies. 
An essential part of the health effects of replacement therapies with oral medications is the prevention of blood-born diseases and their progression. A review of the evidence includes:

(1) A reduction in HIV seroconversion rates in HIVnegative opiate users in comparison to users out of treatment [Abdul-Quader et al., 1987; Schoenbaum et al., 1989; Chaisson et al., 1989; Blix and Grönbladh, 1991; Metzger et al., 1993; Moss et al., 1994; Serpelloni et al., 1994; Gibson et al., 1999].

(2) A reduction in unsafe injection practices, especially needle sharing (a meta-analysis of 8 studies on 1,781 participants comparing MMT patients with users out of treatment, or comparing pre-post values, various durations of treatment or continuous versus interrupted treatment, presented by Marsch [1998], and a recent review of 33 studies including over 17,000 participants by Sorenson and Copeland [2000]).

(3) A better compliance with anti-retroviral medication [Avants et al., 2001] and a reduction in the progression of HIV-related disease [Weber et al., 1990].

Finally, a reduction in mortality rates is documented to be significant as compared to out of treatment heroin addicts [Stenbacka et al., 1998], but methodological problems are mentioned in a meta-analysis of mortality studies [Caplehorn et al., 1996]. However, there is a significant increase in overdose mortality in patients who left methadone maintenance [Appel et al., 2000; Langendam et al., 2001] and again a decrease after readmission [Grönbladh et al., 1990].

Both seroconversions and fatalities occur in the early phase of maintenance treatment. While seroconversions are related to infections acquired before starting treatment or to continued injecting behavior during the first months of treatment, fatal overdose may result from inadequate dosaging or synergistic effects from methadone and other drugs [Caplehorn, 1998]. As in the medical management of other chronic conditions (such as anorexia, rheumatic disorders, deficits from brain injury, etc.), methadone maintenance needs some time to become effective or to stabilize initial improvements. Good retention therefore is a primary objective, and negative outcomes in early dropouts should not account for a discreditation of the treatment per se.

The increase in replacement therapies (mainly methadone and buprenorphine maintenance) during the last decade is to be seen on the background of the threat from blood-born infectious disease and therefore driven by a priority public health interest. The evidence summarized here is much in support of those efforts, especially in countries where opiate injecting and its adverse effects are on the rise and where replacement therapies are an instrument to reduce the speed of the epidemic. Fischer's critical review should not be misused to discredit those efforts; it is welcomed however to further improve future research on effectiveness.

\section{References}

Abdul-Quader AS, Friedman SR, Des Jarlais D, Marmor MM, Maslansky MR, Bartelme S: Methadone maintenance and behavior by intravenous drug users that can transmit HIV. Contemp Drug Probl 1987;14:425-434.

Appel PW, Joseph H, Richman BL: Causes and rates of death among methadone maintenance patients before and after the onset of the HIV/AIDS epidemic. Mount Sinai J Med 2000;67:444-451.

Avants SK, Margolin A, Warburton LA, Hawkins KA, Shi J: Predictors of nonadherence to HIV-related medication regimens during methadone stabilisation. Am J Addict 2001;10:69-78.

Blix O, Grönbladh L: The impact of methadone maintenance treatment on the spread of HIV among i.v. heroin addicts in Sweden; in Loimer N, Schmid R, Springer A (eds): Drug Addiction and Aids. Vienna, Springer, 1991, pp 200-205.

Caplehorn JRM: Deaths in the first two weeks of maintenance in NSW in 1994: Identifying cases of iatrogenic methadone toxicity. Drug Alcohol Rev 1998; 17:9-18.

Caplehorn JRM, Dalton MS, Haldar F, et al: Methadone maintenance and addict's risk of fatal heroin overdose. Subst Use Misuse 1996;31:177-196.

Chaisson RE, Bacchetti P, Osmond D, Brodie B, Sande MA, Moss AR: Cocaine use and HIV infection in intravenous drug users in San Francisco. JAMA 1989;261:561-565.

Dolan KA, Shearer J, MacDonald M, Mattick RP, Hall W, Wodak AD: A randomized controlled trial of methadone maintenance treatment versus wait list control in an Australian prison system. Drug Alcohol Depend 2003;72: $59-65$.

Gibson DR, Flynn NM, McCarthy JJ: Effectiveness of methadone treatment in reducing HIV risk behavior and HIV seroconversion among injecting drug users (editorial). AIDS 1999;13:1807-1818

Gossop M, Marsden J, Stewart D, Treacy S: Outcomes after methadone maintenance and methadone reduction treatments: Two-year follow-up results from the National Treatment Outcome Research Study. Drug Alcohol Depend 2001;62:255-264.

Grönbladh L, Ohlund LS, Gunne LM: Mortality in heroin addiction: Impact of methadone treatment. Acta Psychiatr Scand 1990;82:223-227.

Langendam MW, Van Brussel HA, Coutinho RA, Van Ameijden EJC: The impact of harm-reduction-based methadone treatment on mortality among heroin users. Am J Publ Health 2001;91:774-780.

Marsch LA: The efficacy of methadone maintenance interventions in reducing illicit opiate use, HIV risk behavior and criminality: A meta-analysis. Addiction 1998;93:515-532.

Mattick RP, Breen C, Kimber J, Davoli M: Methadone maintenance therapy versus no opioid replacement therapy for opioid dependence (Cochrane Review). The Cochrane Library. Chichester, Wiley, 2004, issue 2.

Metzger DS, Woody GE, McLellan AT: Human immunodeficiency virus seroconversion among intravenous drug users in- and out-of-treatment: An 18month prospective follow-up. J Acquir Immune Defic Syndr 1993;6:10491056.

Moss AR, Vranizan K, Gorter R, Bachetti P, Watters J, Osmond D: HIV seroconversion in intravenous drug users in San Francisco 1985-1990. AIDS 1994;8:223-231.

Schoenbaum EE, Hartel D, Selwyn PA, Klein RS, Davenny K, Rogers M, Feiner C, Friedland G: Risk factors for human immunodeficiency virus infection in intravenous drug users. N Engl J Med 1989;321:874-879.

Serpelloni G, Carrieri MP, Rezza G, Morganti S, Gomma M, Binkin N: Methadone treatment as a determinant of HIV risk reduction among injecting drug users: A nested case control study. AIDS Care 1994;16:215-220.

Sorenson L, Copeland AM: Drug abuse treatment as an HIV prevention strategy: A review. Drug Alcohol Depend 2000;59:17-31. 
Stenbacka M, Leifman A, Romelsiö A: The impact of methadone on consumption of inpatient care and mortality, with special reference to HIV status. Subst Use Misuse 1998;33:2819-2834.

Weber R, Ledergerber B, Opravil M, Siegenthaler W, Lüthy R: Progression of HIV infection in misusers of injected drugs who stop injecting or follow a programme of maintenance treatment with methadone. BMJ 1990;301: $1362-1365$

\section{Comment}

Robert G. Newman

New York, N.Y.

In his 'Conceptual and Empirical Critique of Methadone Maintenance Treatment (MMT),' Fischer raises a number of valid criticisms of the manner in which MMT is provided, its goals, and the parameters used to evaluate outcome. Unfortunately, he goes on to reveal many of the same distorted perspectives with which he finds fault.

With regard to goals and outcome measures, Fischer characterizes as a 'cross-eyed mission ... the provision of biomedical treatment for social rehabilitation'. To the extent the interests of the community at large are given priority over the needs and wishes of the individual patient, the criticism is valid. But empirical data - and common sense - attest to the concomitant benefits for society as a whole when a heroin addict curtails or stops his/her illicit opiate use. It should also be noted that optimal medical management of any disease focuses on needs and challenges that transcend the strictly physical aspects of the individual patient's disease. Indeed, Fischer himself, after expressing his skepticism over 'social rehabilitation' as a goal of treatment, goes on to disparage the limited effectiveness of MMT in enhancing 'quality of life', addressing 'long-standing psychiatric disorders', etc. - limitations that surely apply to the management of all chronic medical conditions.

In describing the " dysphoric" dynamics of methadone', Fischer fails to distinguish between the arbitrarily imposed policies and practices of providers and the pharmacological effects of the medication. Dysphoria is inevitable in settings where clinicians 'systematically penalize and exclude patients who do not comply with the various rules of treatment'. For example, Fischer is absolutely correct in condemning the counter-therapeutic and counterintuitive use of laboratory tests (urine toxicology) to identify and punish drug use - the pathognomonic feature of the disease being treated. It is equally counter-therapeutic to punish failure to accept 'psychosocial treatment', missed appointments, etc. Policies such as these reflect therapeutic tyranny, rather than the characteristics of the medication. They tell us nothing of its positive and negative effects when used in accord with usual clinical and ethical standards of medical care.

On a somewhat technical note, Fischer seems to confuse two distinct pharmacological actions of MMT, each of which contributes to its effectiveness. One is the development of a high degree of tolerance ('narcotic blockade') that prevents the euphorigenic and most other effects of all opiates, including the maintenance doses of methadone itself. The other pharmacological effect is the diminution or extinction of 'craving' for opiates which is commonly reported by patients. Fischer attacks a strawman when he challenges the thesis that "opioid "narcotic blockade" (in the form of MMT) would alleviate a human agent's craving'.

Fischer is also off the mark in his comments on patient retention in MMT. One reference he cites is of a series of reports in which the median 1-year retention rate is $40 \%$; another referenced program retained almost half its patients for 3 years. Even the lowest MMT rates, however, compare very favorably with those of any other addiction treatment modality. The MMT experience in this regard is especially remarkable in the face of the widespread program policies, discussed previously, that result in 'dysphoria', punishment and treatment termination.

Finally, Fischer is sadly - tragically! - mistaken in the degree of acceptance he attributes to MMT. He comments: 'Over the years, general shortcomings of MMT have been recognized and debated, but none of them have [sic!] managed to effectively challenge the predominant view of MMT as being "effective".' In fact, despite many hundreds of consistent reports of benefits associated with MMT that have appeared for decades from throughout the world, a great many countries continue to ban methadone prescribing altogether, and virtually all the rest impose severe restrictions that are without parallel, and that preclude the majority of opiate-dependent individuals from having access to care that they want and need. Russia is a case in point, adamantly rejecting methadone despite an estimated 2 million addicts, rampant HIV, tuberculosis and hepatitis infection, and a burgeoning addict population in prison. Nor is America, where the concept and practice of methadone maintenance were introduced exactly 40 years ago, that much different: methadone is the only medication in the US pharmacopoeia that cannot be prescribed by community-based 
practitioners, and the programs that have been given the monopoly on its use can accommodate no more than 15$20 \%$ of the estimated heroin addict population.

We know that methadone offers help and hope to a large proportion of those dependent on opiates. We also know that without MMT, the vast majority will be abandoned and become victims of the heightened morbidity and mortality with which addiction is associated. And yet, the prospect that MMT will be permitted to fulfill its lifeenhancing and life-saving potential remains exceedingly slim. Fischer's article won't help!

\section{Reply}

\section{Response to Commentaries by A. Uchtenhagen and R. Newman}

B. Fischer, J. Rehm

Our article 'Eyes Wide Shut' - notably a group- and not single-authored piece of work as seems to be implied by both comments - evidently has triggered a strong reaction from the commentators [1,2]. Although we believe that the evidence presented in the article and the commentaries in large part speak for themselves, a couple of points directly in response to the commentaries may be appropriate for clarification.

Our article was submitted in 2001, and took a very long time to be reviewed and processed; thus, some of the references cited by the commentaries were not available at that time [3, 4].

Overall, our article was written as a critical conceptual and empirical examination of methadone maintenance treatment (MMT) - or a critically reflexive 'devil's advocate' piece, if you will. The objective was not to make an argument or launch a campaign against MMT. Rather, the intent was to critically examine the predominant framing and rationale of the treatment, as well as the nature and quality of the evidence used for broadly and often categorically advocating MMT policy and practice. This examination was in part triggered by the fact that the field is overwhelmed by literature on MMT featuring methodologically weak studies on treatment completers only and on this skewed basis drawing positive conclu- sions about MMT [5]. The other part is the increasing diversity of opioid maintenance treatments. Given this overall situation, the challenge is to find the optimal place of MMT in a diverse landscape of alternative treatments. Finding empirically based treatment matching and system mixes is the challenge of the next years, and given the rather sober experiences of controlled matching studies so far, this will be a daring task to achieve [6,7].

On the conceptual side, addiction - as well as treatment - has always been heavily shaped by ideology and morality politics. The fields of opioid dependence or MMT have not been spared from those determinants (which are socio-cultural constructs and not nature-given), and so they are worthwhile objects for reflexive examination $[8,9]$. MMT may be for many constituents or decision-makers a much more acceptable or desirable intervention if it proves its potential for the reduction of criminal victimization and social costs over individual patient health and well-being. Again, the socio-political context of treatment decisions does not directly influence the effects of a substitution agent or intervention but may provide critical explanations on why alternatives are chosen or privileged.

Similarly, one key trigger for our article when first written was the fact that although there are hundreds of MMT studies, the vast majority are of problematic methodological quality. MMT has been declared 'effective' and pushed on the basis of evidence of a quality that would not suffice for the establishment of a new treatment regimen in many other medical intervention fields [10]. Comparisons of MMT evidence after decades of research, as exemplified by the recent Cochrane Review, compared to reviews for other medications, are helpful in understanding the real dynamics of adopting new medication, aside from repetitions of evidence-based principles [3].

On this basis, we believe that the intentions of both our author collective as well as the commentators aim at the same goal: to provide the best possible interventions and treatment for the very real problem of opioid dependence or co-dependence. We also agree on the fact that currently MMT plays an important role in this effort. We seem to differ when it comes to defining this role in the mix of modern intervention systems. In our view, having established some efficacy or even effectiveness of one treatment cannot and does not automatically determine its role in social intervention systems, neither for methadone nor for buprenorphine nor for heroin. Thus, rather than reaffirming support for certain treatment regimes within 'for-or-against' paradigms, we should systematically and empirically examine advantages and disadvantages of dif- 
ferent interventions in systems and 'real life' contexts, including consumer or quality of life perspectives [11]. Finally, we should additionally keep in mind that in the illicit drug field at the beginning of the 21 st century, ideological and political pressures continue to be powerful forces, often influencing or compromising strongest evidence or best practice.

\section{References}

1 Uchtenhagen A: Solid evidence for the effectiveness of methadone maintenance therapy (commentary). Eur Addict Res 2004, this issue.

2 Newman R: Commentary. Eur Addict Res 2004, this issue.

3 Mattick R, Breen C, Kimber J, Davoli M: Methadone maintenance therapy versus no opioid replacement therapy for opioid dependence (Cochrane Review). Cochrane Library. Chichester, Wiley, 2004, issue 2.

4 Dolan K, Shearer J, MacDonald M, Mattick R, Hall W, Wodak A: A randomised controlled trial of methadone maintenance treatment versus wait list control in an Australian prison system. Drug Alcohol Depend 2003;72: $59-65$.
5 Fischer B, Kirst M, Rehm J, Marsh D, Bondy S, Tyndall M: The phenomenon of so-called 'other drug use' among opiate addicts in the North American context: Evidence, consequences, questions; in: Westermann B, Bellman G, Jellinek C (eds): Beigebrauch: Offene Grenzen der Substitution. Weinheim, Beltz Deutscher Studienverlag, 2000, pp 95-118.

6 van den Brink W, Hendriks V, van Ree J: Medical co-prescription of heroin to chronic, treatment-resistant methadone patients in the Netherlands. J Drug Issues 1999;29:587-608.

7 Rehm J, Fischer B: Deutsche Suchtforschung im Wandel - Perspektiven für die Zukunft. Sucht 1997;43:163-169.

8 Musto D: The American Disease: Origins of Narcotic Control. New York, Oxford University Press, 1987.

9 Fischer B: Prescriptions, power and politics: The turbulent history of methadone maintenance in Canada. J Public Health Policy 2000;21:187-210.

10 National Institutes of Health: National consensus development panel on effective medical treatment of opiate addiction. JAMA 1998;280:19361943.

11 Fischer B, Rehm J, Kim G: 'Quality of life' (QoL) in illicit opiate addiction research and treatment: Concepts, evidence, questions; in Westermann B, Jellinek C, Bellman G (eds): Substitution: Zwischen Leben und Sterben. Weilheim, Beltz Deutscher Studienverlag, 2001. 